\title{
MANUTENÇÃO DE COLÔNIA DE ANOPHELES DARLINGI ROOT, 1926, EM LABORATORIO (1)
}

\author{
Geraldo Magela BURALLI (2) \& Eduardo Sterlino BERGO (2)
}

\begin{abstract}
RESUMO
Descreve-se a instalação e manutenção inicial de uma colônia de An. darlingi, no município de Araraquara, SP, como parte do programa de pesquisas em malária da Superintendência de Controle de Endemias - SUCEN.

Participando-se de experienncia semelhante descrita por CORREA na década de 70, aprescnta as modificaçòes sugeridas por outros autores e pela experiência de scis meses de funcionamento. A perspectiva é de desenvolvimento de uma colônia com simplificaçòes de tecnicas e equipanentos.

São dadas informaçoss sobre alimentação de larvas e alados, duração dos estadios larvais, mortalidade e acasalamento.
\end{abstract}

UNITERMOS: Anopheles darlingi - insetário.

\section{INTRODUÇÃO}

A criação em massa de anofelinos em laboratório é vista atualmente como condição precípua ao desenvolvimento de pesquisas em malária já que grande parte dos est udos requer a manutenção do ciclo esporogônio de plasmódios.

A escolha da espécie a ser colonizada recai, em geral, naquelas de comprovada capacidade vetorial e preferencialmente com ampla distribuição geográfica, tanto pela disponibilidade de exemplares para início e reforço do insetário quanto pela facilidade, que se espera, na reprodução das condições ambientais, em laboratório, exigidas pela espécie. Entretanto, é fato conhecido de quantos tenham se dedicado a essa tarefa que certas espécies, aparentemente pouco exigentes de condições climáticas especiais, na verdade devem ter seu desenvolvimento con- dicionado a alto grau de especialização ecológica, envolvendo biocenoses essenciais e complexas de difícil reprodução+.

Nesse sentido, Anopheles darlingi tem-se constituido num desafio para os pesquisadores brasileiros. Por ser a espécie de maior importância na veiculação das malárias humanas no pais, graças à elevada suscetibilidade a $\mathbf{P}$. vivax e P. falciparum, endofilia e antropofilia acentuadas e ocorrência relativamente farta em ambientes com diferentes graus de interferência antrópicat, tem-se prestado a várias tentativas de colonização artificial, em geral mal sucedidas.

Esse insucesso na manutenção das colônias provavelmente tem desestimulado a publicação de resultados parciais, que se verifica pela es-

(1) Auxílio financeiro do CNPq-Polonoroeste 700349/85

(2) Superintendencia de Controle de Endemias-SU CEN, Rua Paula Souza, 166. CEP 01027 São Paulo, SP, Brasil. 
BURALl.I. G.M. \& BERGO, E.S. - Manutenção de colônia de Anopheles darlingi Root, 1926, emn laboratório. Rev. Inst. Med. trop. São Paulo, 30(3):157-164, 1988 .

cassa liceratura disponivel, o que contribue anda mais para as dificuldades que se tritrenta na sua criação.

Desde os trabahos pioneiros realizados ate 1950, por autores nacionais e estrangeiros, a principal informação disponivel provém de comunicaçōes pessoais de técnicos que participaram dessas experiências ou de relatórios de divulgação restrita $1,2,5,7,9,11$. De qualquer forma, pode-se dizer que existe hoje um conhecinento acumulado razoável que permite dar inicio a uma colonia de An. darlingi e que a maior dificuldade se refere a sua manutençào por longos períodos. A análise das experiências referidas rostra que alguns parâmetros fundamentais es tào ben. estabelecidos como: necessidade de tgua hine, de origem natural, para manuteiGo das larvac; alimentos mais aceitos; extgëncia de gaiola de grande porte para permitir a corte e copula e os recipientes de oviposicão capazes de simular o criadouro natural de grande prolundiade.

Entre esses trabalhos destaca-se o de COR REA " que conseguiu manter no municipio de Araraquara, SP, por cerca de dez anos, uma colonia cuja produçăo diária de adultos atingiu, no ápice da sua atividade, a média de 1.500 cxemplares.

A experiência atual da SUCEN $*$ buscando a reinstalação da colônia, significa assim uma tentativa de resgatar o conhecimento acumulado por aquele autor e pelos técnicos que o acompanharam. Ela faz parte do programa de pesquisa em malária da autarquia que, no momento pretende manter o cultivo "in virro" de formas hepáticas do parasita a partir de esporozoilos, alem de trabalhos voltados ao esiudo da suscetibilidade às corogas antimalaricas.

A nova colónia teve inicio em mano de 1987, quando se optou por utilizar a mesma netodologia desenvolvida por CORREA a a pamir da buscar as adaplacoes que se julgaren necesarias. A descricáo dessas ativiade ignifica o registo de experiencia prelimina uleita portanto, a critica adaptaça con anter.

\section{MATERIAL E MÉTODOS}

Instabòes, móveis a equipamentins:

O prédio que abriga o inserario projotados construido especiamente para esse fim, esta sinado em Araraquara, SP, a $275 \mathrm{~km} \mathrm{da} \mathrm{Ca-}$ pital.

A area total construida é de $55 \mathrm{n}$ - composla por um laboratório, sala de criaça de larvas, sala de criação de alados, sala de criação de coelhos e depósitos, conforme tig. 1. As paredes sào revestidas de azulejos e o piso de ceràmica esmaltada. O teto é de laje de concreto, com cobertura de telhas de barro. A entrada do prédio é protegida por dupla porta, sendo uma de 1ela. Internamente existem cortinas de algodäo isolando o hall de entrada e aquele que dá acesso às salas de criação. Todas as janelas são leladas.

O laboratório é equipado com móveis e aparchos convencionais. A sala de criação de larvas apresenta pequena bancada com pia estantes de madeira revestindo as paredes. A saia de manutenção de alados contém duas gaiolas para mosquitos e uma mesa de manipulaçào. As duas salas de criação estão equipadas com aquecedores elétricos e umidificadores. O controle da temperalura e umidade relativa é feito por termómetros e termohigrógafo.

A iłuminação artificial é feita por lânpadas fhuorescentes.

\section{Coleta de alados e produção de ovos:}

Fêmeas selvagens de An. darlingi sào capturadas nos períodos crepusculares, no Município de Dourado, SP, distante $50 \mathrm{~km}$ do insetário, às margens do Rio Jacaré-Pepira. Os exemplares são coletados individualmente, com isca humana, em frascos de vidro vasados de $2 \times 5$ $\mathrm{cm}$, com dedais de tela em ambas as extremidades (tubos Corrêa). As fêmeas são alimentadas com algodão embebido em solução de sacarose a $10^{\%}$ e transportadas ao laboratório, onde sào identificadas colocando-se diretamente o tubo sob o microscópio.

Após a identificação são colocadas, em grupos de 10 , em copos plásticos de $500 \mathrm{ml}$, telados, com fundo de algodão e papel filtro úmido para oviposicào. O interior dos copos é lixado para permitir o repouso nas laterais.

As fêmeas são alimentadas diariamente, com sangue humano, diretamente no braço. Recentemente este tipo de alimentaçào vem sendo substituido por camundongos anestesiados $\mathrm{e}$ colocados diretamente sobre os copos.

Us ovos são coletados a cada dois dias, por lavagem do papel filtro nas bandejas de criação de larvas. 
BURALLI, G.M. \& BERGO, E.S. - Manutenção de colônia de Anopheles darlingi Root, 1926, em laboratório. Rev. Inst. Med. trop. São Paulo, 30(3):157-164, 1988 .

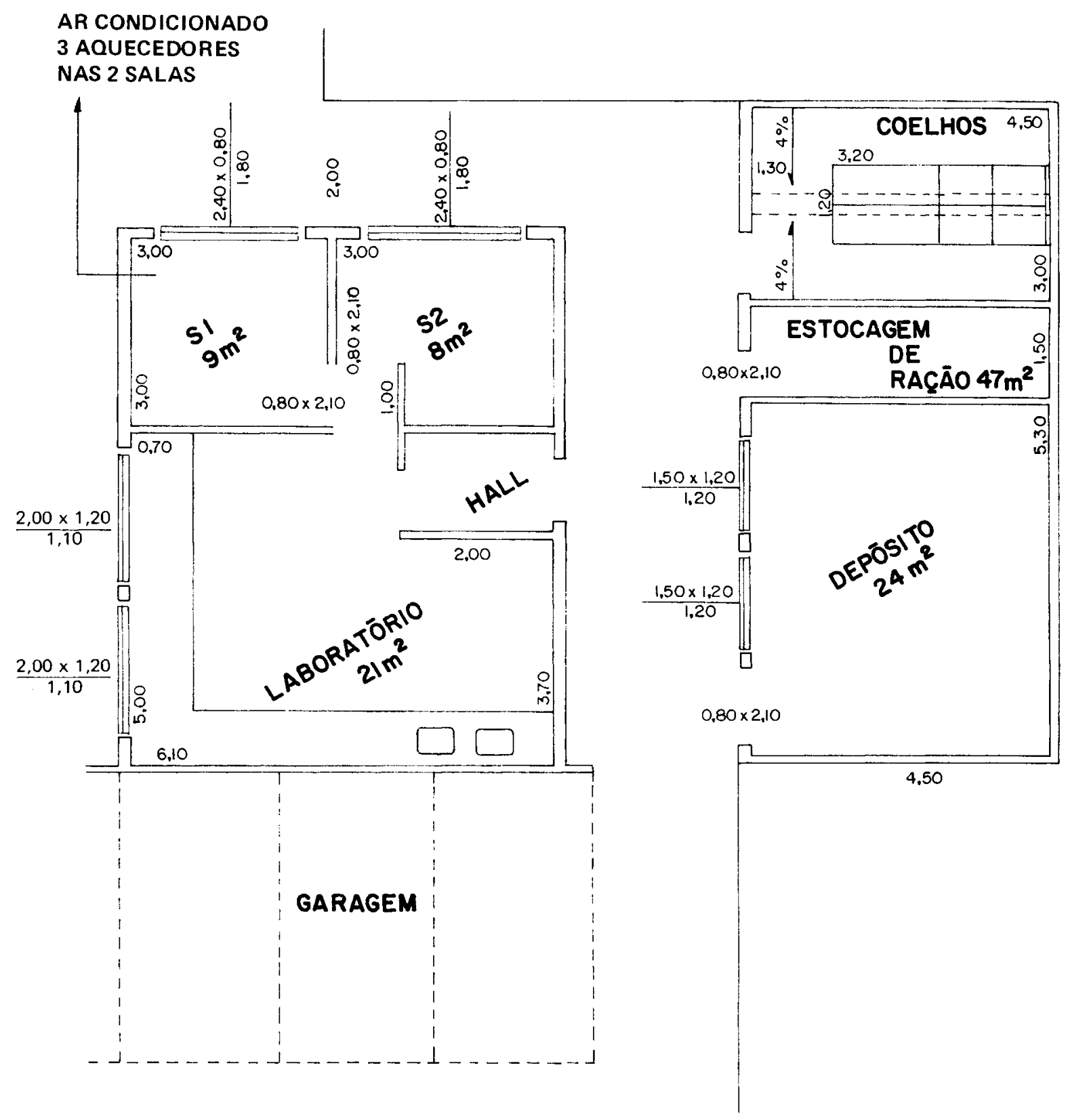

\section{Criação de larvas:}

As larvas são criadas em bandejas de plástico, circulares, com $25 \mathrm{~cm}$ de boca e $10 \mathrm{~cm}$ de altura. Essas bandejas, tipo bacia, são de baixo custo e facilitam a limpeza. A água é proveniente de fonte natural e permanece em galões plás- ticos no interior da sala para equilíbrio da temperatura. A troca de água é feita diariamente pelo seguinte processo: despeja-se a água com as larvas em uma bandeja limpa; nesta, provoca-se um movimento circular na água com uma pera de borracha de bico longo para que o sedimento restante (alimento, exúvias e 
BuRALli, G.M. \& BERGO, E.S. - Manutenção de colônia de Anopheles darlingi Root, 1926, em laboratório. Rev. Inst. Med. trop. São

Paulo, 30(3):157-164, 1988.

larvas mortas) se acumule no centro do fundo da bandeja; aspira-se o resíduo e a água, pelo fundo, até reduzir o volume a uma lâmina de água; completa-se o volume com água limpa.

Para a alimentação utilizou-se uma mistura de partes iguais de farinha de milho, ração para aves de corte, ração para pássaros e fermento para biscoito de polvilho, moídos e peneirados. Complementa-se a alimentação com fermento Fleischmann. Após experimentos com diferentes rações, optou-se por aquela proposta por SANTOS10 que se constitui na mistura de uma parte de farinha de peixe para duas de pào torrado e moído e duas de germe de trigo. Não é utilizado qualquer tipo de levedura viva.

A ração é oferecida diariamente na quantidade aproximada de 0,3 a $0,6 \mathrm{mg} /$ larva de acordo com o estadio larval predominante na bandeja, segundo o proposto por GERBERG ${ }^{*}$. O número médio de larvas por bandeja é de 200 exemplares.

A disposição seqüencial das bandejas em prateleiras permite visualizar a evoluçào das larvas pela distribuição dos diferentes estadios larvais em diferentes alturas da estante.

A coleta de pupas é feita diariamente pela aspiração individual com pipeta Pasteur. Estas pupas são contadas e colocadas para eclosão em frascos com tampa adaptada em "funil invertido". Isto impede a entrada de alados no frasco de pupas.

\section{Manutenção de alados:}

As gaiolas de alados medem, cada uma, $1 \mathrm{~m}$ de largura por $1 \mathrm{~m}$ de altura por $0,60 \mathrm{~m}$ de lado. A base e o teto são de madeira maciça suportados por sarrafos. As laterais e o fundo são feitos de tecido de algodão. A frente é de tela de nylon, malha 20, e apresenta duas aberturas protegidas por manga de malha de algodão: uma superior, pequena, e uma rente à base, com $0,30 \mathrm{~m}$ de boca. A abertura superior permite a manipulaçào de mosquitos e das fontes de alimentação não sanguínea. A abertura inferior permite a limpeza do fundo da gaiola e a colocação da fonte de alimentação sanguínea.

$O$ primeiro alimento citado compõe-se de bolas de algodão embebidas em solução de sacarose a $10 \%$ e fatias de maçà ou beterrabas, penduradas no teto.

A alimentação sanguínea é feita sobre o dorso de coelhos com área depilada. Os coelhos permanecem imobilizados em caixas de contençào. Esta caixa compōe-se de uma base de madeira em cuja extremidade existe uma cela com abertura em guilhotina, onde o animal fica preso pelo pescoço. Esta caixa visa protegê-lo de picadas no focinho e orelhas que são áreas muito sensiveis. A estrutura e medidas da caixa de contenção podem ser vistas na figura 2 .

A alimentação sanguínea, em coelhos, é oferecida diariamente aos mosquitos por cerca de três horas.

Além das aberturas frontais existe uma outra, lateral, destinada à oviposição. A metade inferior de uma lateral não tem tecido e se estende na forma de túnel de filó até a boca de um cristalizador de vidro, de $30 \mathrm{~cm}$ de diâmetro por $30 \mathrm{~cm}$ de altura. Essa manga de filó é presa por sarra os de madeira na gaiola e amarrada à boca do cristalizador. Este, com água até $2 / 3$ de altura, permanece dentro de um aquário, com fundo escurecido. Este conjunto simula, para as fêmeas grávidas, um criadouro amplo e de grande profundidade.

Diariamente, o cristalizador é descoberto e sâo coletados os ovos com tiras de papel filtro. Os ovos coletados são semeados em bandejas identificadas, as quais são levadas para a sala de criação de larvas.

O acompanhamento da população de alados na gaiola é feito pelo registro diário de três dados: no de pupas vivas que entram, n? de pupas mortas retiradas e n? de alados mortos. Estes últimos são coletados a partir da limpeza do fundo da gaiola, com o auxílio de um aspirador, e daqueles que morrem na superfície do cristalizador de oviposição.

Quanto às condiçōes climáticas, procurase manter a temperatura das salas entre 25 a $27^{\circ} \mathrm{C}$ e a umidade relativa do ar acima de $70 \%$. $O$ fotoperiodo é de aproximadamente 12 horas luz, 12 horas sombra. Durante o dia, a luminosidade mantém-se reduzida à penumbra, graças às telas escuras das janelas (sombrite) e persianas horizontais.

\section{RESULTADOS E COMENTÄRIOS}

$\mathrm{Na}$ instalação desse insetário optou-se, como já foi dito, por iniciar a colônia partindo-se da metodologia desenvolvida por (ORREA. mesmo que algumas técnicas já tivessem sido testadas com sucesso por outron autores. Lstas seriam incorporadas paulatinamente. Ainda co- 
BURALLI, G.M. \& BERGO. E.S. - Manutenção de colònia de Anopheles darlingi Root, 1926, em laboratório. Rev. Inst. Med. trop. São Pauio, 30(3):157-164, 1988 .

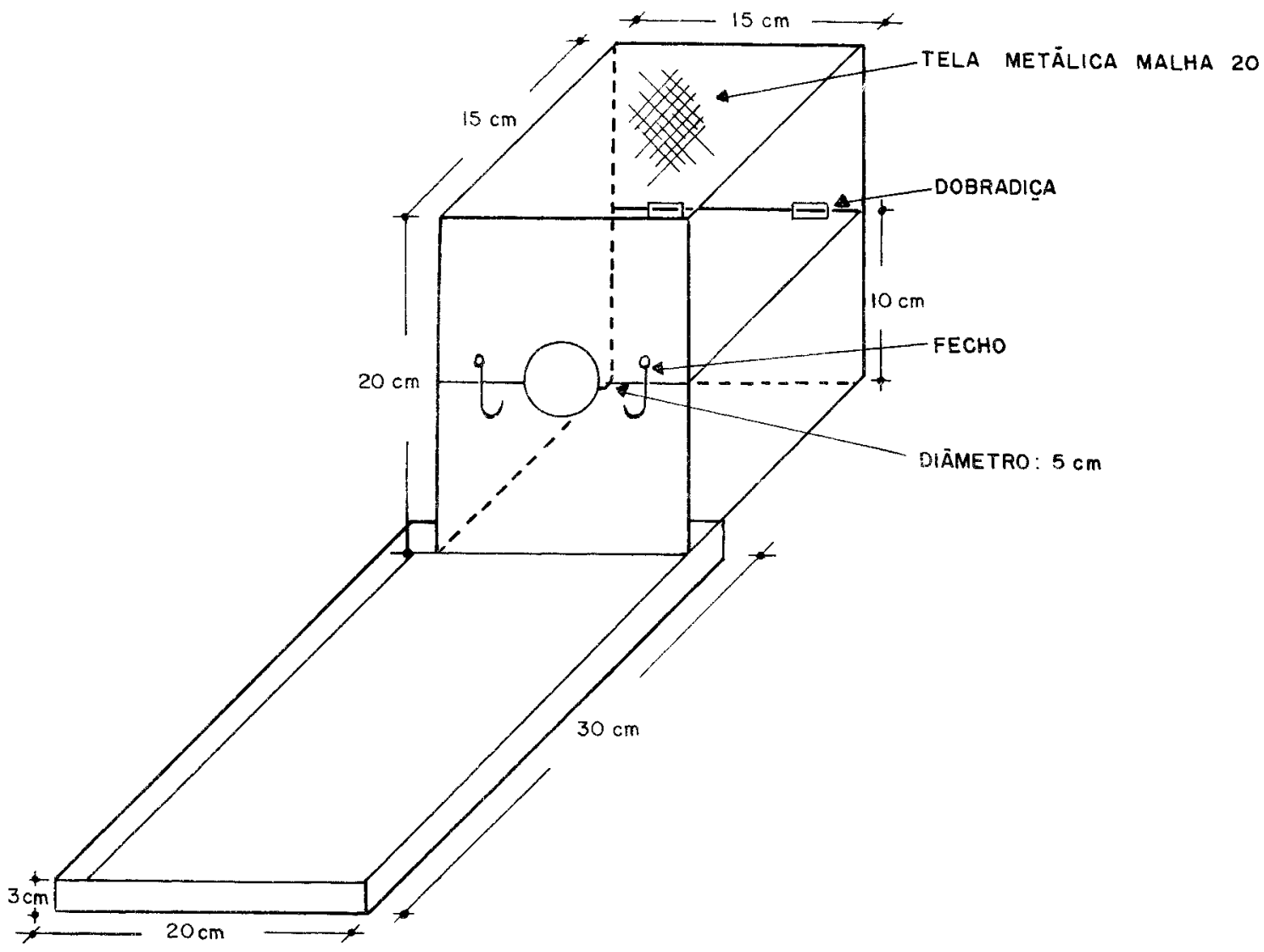

mo opção de trabalho procurou-se desenvolver um insetário de produção em massa de mosquitos, sem privilegiar procedimentos que, embora fornecedores de dados sobre a biologia da espécie, viessem sobrecarregar o trabalho como, contagem de ovos e larvas nos diferentes estadios, determinação de taxas de eclosão, sobrevivência, etc. Estas observações deverão ser feitas em experimentos paralelos, utilizando-se grupos de insetos restritos.

Quanto a tentativa de repetição da experiência original verificou-se um fato já esperado, qual seja, os resultados obtidos por aquele autor, numa situação de colônia bem estabelecida, nem sempre são reprodutiveis no início da colônia, mesmo se mantendo rigorosamente as técnicas utilizadas. Isto se deve provavelmente ao "status" genético das populações seguramente com diferentes graus de adaptação às condições de laboratório.
Em vista disso observa-se que a colônia, nesse primeiro ano de existência, ainda apresenta grande dependência da introdução de ovos provenientes da população selvagem. A maior densidade de individuos acompanhou assim as variaçōes sazonais da população natural, cujo ápice ocorre no período de maio a agosto.

$O$ esquema de manutenção da colônia diferiu da de CORRÊA 5 quando se procurou trabalhar com duas populações distintas. Para isso foram utilizadas duas gaiolas, uma das quais recebia apenas os adultos $\left(F_{1}\right)$ nascidos da geração do campo (parental). Essa geração, portanto $F_{\text {, }}$, era colocada em bandejas separadas e os alados resultantes eram colocados na segunda gaiola. Desta forma esperava-se contar com uma gaiola de $F_{1}$, com introdução permanente de indivíduos selvagens, e outra, onde se teria uma população mais adaptada às condiçôes de laboratório. Os ovos colhidos nessa segunda 
BURAlLi, G.M. \& BERGO, E.S. -- Manutençăo de colôna de Anopheles darlingi Root, 1926, en labotatorio. Rev. Inst. Med. trop. São Paulo, 30(3): 157-164, 1988 .

TABHIA

Produção de exemplares de An. darlingi (geração $F_{1}$ ) no periodo de junho a novembro de 1987.

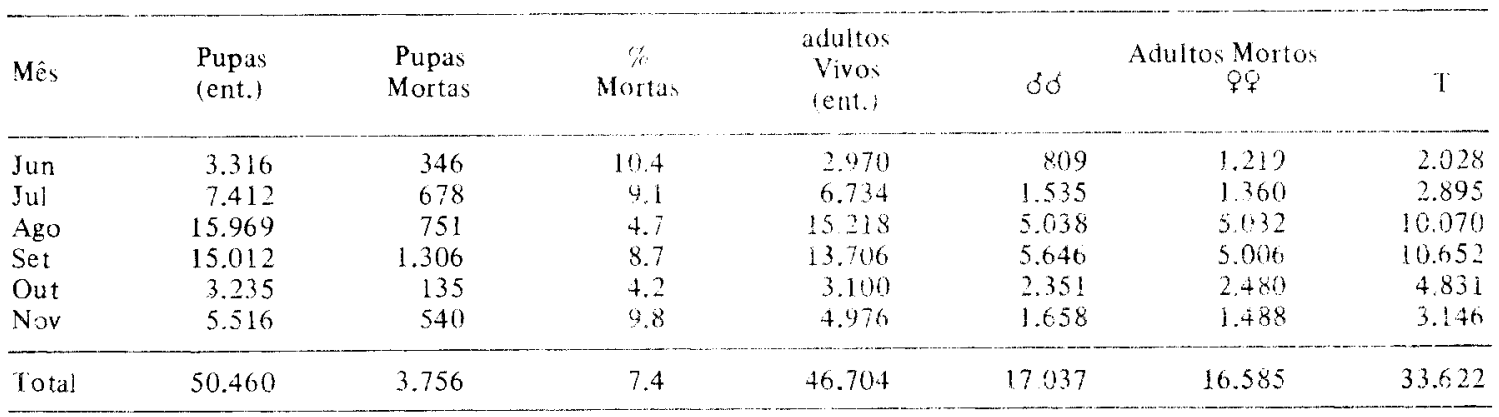

TABELA 2

Produção de exemplares de An. darlingi (geração $\mathrm{F}_{2}$ ) no periodo de junho a novembro de 1987.

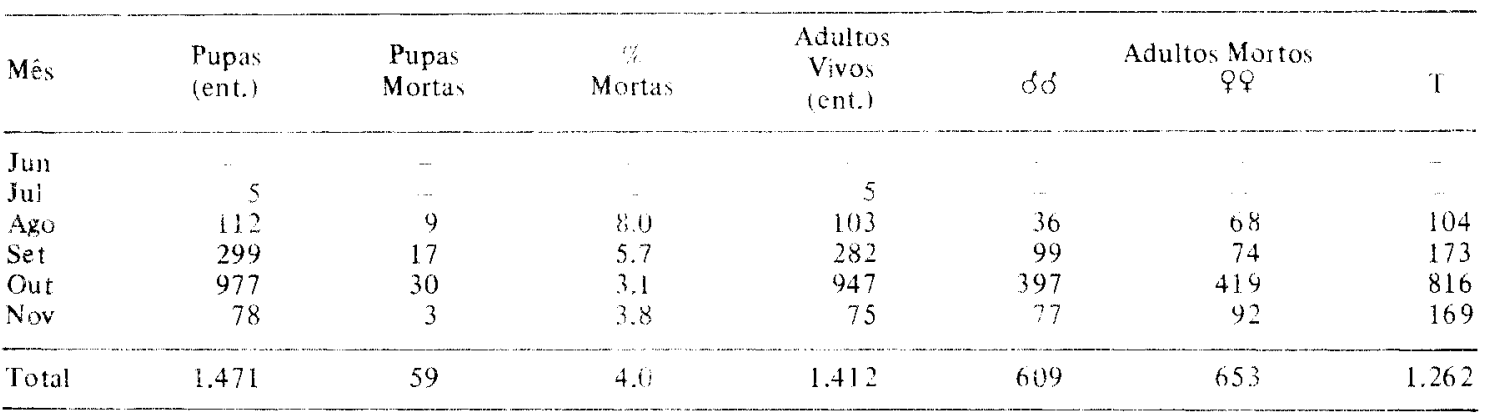

gaiola gerariam adultos que voltariam a integrar essa mesma população.

Esse esquema foi seguido nos seis primeiros meses de trabalho e nào pode ser mantido devido a queda na população $F_{1}$. Conseqüente mente o número de individuos $F$, nào toi suficiente para permitir cópula e oviposiçào. Os datdos das tabelas 1 e 2 mostram os resultados obtidos nesse período.

Como se verifica, as maiores densidades obtidas na gaiola de $F_{1}$ ocorreram nos meses de agosto e setembro como consequência do elevado número de ovos colhidos nos meses anteriores a partir de fêmeas do campo. Esse fato se repete em $F$, com maior produção em setembro e outubro.

Os dados apresentados nas tabelas acima devem ser vistos apenas como registro de produção, visto que não permitem concluir sobre taxas de mortalidade geral ou por sexo. Apenas chama-se a atenção para a elevada mortalidade de pupas. A causa principal é a contaminação por fungos que crescem nos frascos onde as pupas sào postas a eclodir dentro das gaiolas de alados. Esses fungos estão sendo estudados visando a adoção de substâncias inibidoras no meio sem prejuizo para os insetos. Até o momento sabe-se que ocorrem duas especies filamentosas e uma levedura, que envolvem as pupas dificultando a sua mobilidade.

Quanto a mortalidade de adultos, embora não se disponha de avaliaçào da sobrevivência diaria, deve-se registrar que periodicamente ocorrem grandes baixas na populaça. Acredita-se que isto ocorra em virtude de alteraçoes bruscas na umidade relativa na sala de manutençào de alados.

A temperatura nesta sala tem sido mantida abaixo $27^{\circ} \mathrm{C}$ e a umidade relativa acima de $70 \%$. Entretanto, tem-se registrado elevacões de temperatura ao redor de $30^{\circ} \mathrm{C}$. principalmente nos dias mais quentes, com difícil manutençào da umidade relativa elevada. Os ap rethos convencionais de correçào dessas variáveis 
BLiRAlli, (j.M. \& BERGO, E.S. - Manutenção de colónia de Anopheles darlingi Root, 1926, em laboratório. Rev. Inst. Med. irop. São Paulo, 30(3): 157164,1988

tem-se mostrado ineficazes. O uso de ar condicionado mostrou-se totalmente inadequado.

Atualmente estão sendo feitas adaptaçōes na estrutura do prédio visando maior isolamento térmico com o exterior.

Ainda com relação a manutenção de alados, pode-se dizer que a alimentaçào não sanguínea tem-se mostrado satisfatória. A introduçâo de beterraba, juntamente com maçãs e solução de sacarose, além de atrativa para os mosquitos, facilita a operação dada a sua maior resistência a dessecação e proliferação de micro organismos fermentadores.

O mesmo não se observa na alimentação sangüinea. A oferta de coelho não tem dado re sultados tão satisfatórios como foram conseguidos por CORREA $"$. A proporção de fêmeas engurgitadas é baixa, o que deve explicar a baixa produção de ovos. Esta fonte de repasto sangüineo vem sendo substituída, com resultados promissores, por ratos brancos de laboratório. Os animais são anestesiados, colocados numa rede de filó e pendurados no teto da gaiola.

Quanto ao acasalamento pode-se dizer que é uma das principais barreiras a serem vencidas na colonização de An. darlingi ${ }^{\times}$. O uso de gaiolas pequenas, que dão grande agilidade no manejo de espécies estenogâmicas não tem-se mostrado adequadas para a criação dessa espécie. A gaiola utilizada, com $1 \mathrm{~m} \times 1 \mathrm{~m} \times 0,6 \mathrm{~m}$, mostrou que permite o vôo nupcial, com cópula, quando a população ultrapassa 2.500 exemplares. Quando a população de alados cai abaixo desse valor, a produção de ovos torna-se intermitente.

Dos resultados obtidos até o momento os mais consistentes referem-se a criação de larvas. Tanto na parte operacional (uso de bandejas, troca de água, etc) como no que diz respeito ao desenvolvimento larvário a colônia é satisfatória.

Em experimentos paralelos onde foram acompanhados grupos de 100 larvas mantidas individualmente, porém nas mesmas condições climáticas e de alimentação da colônia foi possivel medir o tempo de desenvolvimento larvário bem como a mortalidade, pelo método de determinação do estadio mediano, como segue:

$$
\text { estadio duração (dias) mortalidade }(\%)
$$

$\begin{array}{lll}\text { I } & 2,7 & 2,4 \\ \text { II } & 1,7 & - \\ \text { III } & 2,2 & -\end{array}$

$\begin{array}{lrl}\text { IV } & 4,5 & 1,03 \\ V \text { (pupa) } & 1,7 & 3,03 \\ \text { I-V } & 12,8 & 6,10\end{array}$

Ainda que estes dados se refiram a larvas mantidas isoladamente, portanto livres da com petição existente nas bandejas, eles confirmam a observação diária onde se constata reduzida mortalidade de larvas.

A ração ora em uso mostrou vantagens sobre aquela utilizada por CORREA ${ }^{5}$ quanto ao tempo de desenvolvimento larvário. Quanto à mortalidade os dados são semelhantes. Ressalta-se ainda que essa ração dispensa a complementação alimentar com leveduras, com seus inconvenientes, e é feita a partir de produtos facilmente encontrados no mercado.

Em vista dessas considerações, várias adaptações estão sendo feitas na metodologia de manutençào da colônia, sempre numa perspectiva de simplificação tanto dos equipamentos quanto das técnicas utilizadas.

\section{SUMMARY}

\section{Maintenance of Anopheles darlingi, Root, 1926, in laboratory}

The authors describe the installation and the initial efforts to maintain Anopheles darlingi laboratory colonies in Araraquara $\mathrm{SP}$, as part of the Malaria Research Program SUCEN

Based on other investigators' suggestions and on their own experience in the first six months of work, the authors present some modifications to the original methods of insect rearing, described by CORREA in the $70^{\circ} \mathrm{s}$. The aim is to maintain insect colonies, using simple techniques and equipment.

Information on larval and adult feeding, duration of larval instars, insect mortality and mating are provided.

\section{AGRADECIMENTOS}

Agradecemos aos técnicos Antenor Seisdedos, Luiz Zaia, João Mauricio N. da Silva, José Antonio Zuanon e José Carlos Gabarron. 
BLRALL, G.M. \& BERGO, E.S. - Manutenção de colônia de Anopheles darlingi Root, 1926, em laboratorio. Rev. Inst. Med. Irop. São Paulo, 30(3): 157-164, 1988

\section{REFERÊTCIAS BIBLIOGRÁFICAS}

1. BARRETO M.P. \& COUTINHO, J.O - Criąào de algumas espécies de anofelinos brasileiros. Rev. bras. Biol., 3: 317-323, 1943.

2. BATES, M - The laboratory colonization of Ano pheles darlingi. J. nat. Malar. Soc., 6: 155-158, 1947

3. BERGO, E.S.; BURALLI, G.M.; PRADO, M.A.N. ALMEIDA, M.G. \& SANTOS, J.L.F. - Avaliação do desenvolvimento e do estado nutricional de Anopheles darlingi Root, 1926, criado em laboratório sob diferentes dietas. São Paulo, 1988. 12 p. (Projeto e relatório parcial apresentados à Comissão Cientifica Permanente da Superintendencia de Controle de Endemias SUCEN).

4. COLUZZI, M. - Maintenance of laboratory Colonies of Anopheles mosquitoes. Bull. Wld. Hith. Org., 31: $441-443,1964$

5. CORREA, R.R.; FERREIRA, E.; RAMALHO, G.R \& ZAIA, L. - Informe sobre uma colônia de Anophe- les darlingi - São Paulo. In: CONGRESSO BRASIL.EIRO DE HIGIENE, 18., São Paulo, 1970. p. 80 , res. n? 107

6. FORATTINI, O.P. - Entomologia médica. São Pau lo, Faculdade de Higiene e Saude Pública, 1962. v. 1.

7. FREIRE, S.A. \& FARIA, G.S. - Criaçào e alguns dados sobre a biologia do Anopheles darlingi. Rev. bras. Biol. 7: $57-66,1947$

8. GERBERG, E.J. - Manual for mosquito rearing and experimental techniques. Amer. Mosq. Control Ass. Bull., (5): 1-109, 1970.

9. GIGLIOL1, G. - Laboratory colony of Anopheles darlingi. J. nat. Malar. Soc., 6: 159-164, 1947.

10. SANTOS, J.M.; CONTEL, E.P.B. \& KERR, W.E. Biologia de anofelinos amazônicos. 1 - ciclo biológico, postura e estadios larvais de Anopheles darlingi, Root, 1926 (Diptera: culicidae) da Rodovia Manaus Boa Vista. Acta amaz. (Manaus), 11: 789-797, 1981

11. SUPERINTENDENCIA DE CONTROLE DE ENDEMIAS (SUCEN). Relatório: Atividades de entomologia desenvolvidas em Araraquara. São Paulo, 1979. 